\title{
Relationship Between Plasma Glucose and Insulin Concentration, Glucose Production, and Glucose Disposal in Normal Subjects and Patients with Non-Insulin-dependent Diabetes
}

\author{
Y.-D. Ida Chen, Chii-Y. Jeng, Clarie B. Hollenbeck, Min-S. Wu, and Gerald M. Reaven \\ Department of Medicine, Stanford University School of Medicine, Palo Alto, California 94305; and Geriatric Research, \\ Education and Clinical Center, Veterans Administration Medical Center, Palo Alto, California 94304
}

\begin{abstract}
The changes in hepatic glucose production $\left(R_{\mathrm{a}}\right)$, tissue glucose disposal $\left(\boldsymbol{R}_{\mathrm{d}}\right)$, and plasma glucose and insulin concentration that took place over a 16-h period from 10 to 2 p.m. were documented in 14 individuals; 8 with non-insulin-dependent diabetes mellitus (NIDDM) and 6 with normal glucose tolerance. Values for $\boldsymbol{R}_{\mathrm{a}}$ were higher than normal in patients with NIDDM at 10 p.m. (4.73 \pm 0.41 vs. $3.51 \pm 0.36 \mathrm{mg} / \mathrm{kg}$ per $\mathrm{min}$, $P<0.001$ ), but fell at a much faster rate throughout the night than that seen in normal subjects. As a consequence, the difference between $R_{\mathrm{a}}$ in normal individuals and patients with NIDDM progressively narrowed, and by 2 p.m., had ceased to exist (1.75 \pm 0.61 vs. $1.67 \pm 0.47 \mathrm{mg} / \mathrm{kg}$ per $\mathrm{min}, P=\mathrm{NS})$. Plasma glucose concentration also declined in patients with NIDDM over the same period of time, but they remained quite hyperglycemic, and the value of $245 \pm 27 \mathrm{mg} / \mathrm{dl}$ at $2 \mathrm{p} . \mathrm{m}$. was about three times greater than in normal individuals. Plasma insulin concentrations also fell progressively from 10 to 2 p.m., and were similar in both groups throughout most of the 16-h study period. Thus, the progressive decline in $R_{\mathrm{a}}$ in patients with NIDDM occurred despite concomitant falls in both plasma glucose and insulin concentration. Glucose disposal rates also fell progressively in both groups, but the magnitude of the fall was greater in patients with NIDDM. Consequently, $R_{d}$ in patients with NIDDM was higher at 10 p.m. (3.97 \pm 0.48 vs. $3.25 \pm 0.13 \mathrm{mg} / \mathrm{kg}$ per $\mathrm{min}, P<0.001)$ and lower the following day at 2 p.m. (1.64 \pm 0.21 vs. $1.97 \pm 0.35 \mathrm{mg} / \mathrm{kg}$ per $\mathrm{min}, P$ $<0.01)$. These results indicate that a greatly expanded pool size can exist in patients with NIDDM at a time when values for $\boldsymbol{R}_{\mathrm{a}}$ are identical to those in normal subjects studied under comparable conditions, which suggests that fasting hyperglycemia in NIDDM is not simply a function of an increase in $R_{\mathrm{a}}$.
\end{abstract}

\section{Introduction}

Hyperglycemia can only develop when the rate of entry of glucose into plasma $\left(R_{\mathrm{a}}\right)^{1}$ exceeds its rate of disposal $\left(R_{\mathrm{d}}\right)$. In

Address all correspondence to Dr. Gerald M. Reaven, Veterans Administration, GRECC/182B. 3801 Miranda Avenue, Palo Alto, CA 94304.

Received for publication 29 June 1987 and in revised form 4 November 1987.

1. Abbreviations used in this paper: ANOVA, analysis of variance; NIDDM, non-insulin-dependent diabetes mellitus; $R_{\mathrm{a}}$, rate of entry of glucose into plasma; $R_{\mathrm{d}}$, rate of disposal of glucose from plasma.

The Journal of Clinical Investigation, Inc.

Volume 82, July 1988, 21-25 normal subjects this occurs throughout the day in response to meals, and postprandial hyperglycemia is clearly a situation in which $R_{\mathrm{a}}$ exceeds $\boldsymbol{R}_{\mathrm{d}}$. However, this condition is quite transitory, within a short time $R_{\mathrm{a}}$ and $R_{\mathrm{d}}$ are again equal, and euglycemia exists for most of the daily $24-\mathrm{h}$ period in individuals with normal glucose tolerance. In contrast, hyperglycemia is continuously present in patients with non-insulin-dependent diabetes mellitus (NIDDM), and questions remain as to the relative contribution of changes in $R_{\mathrm{a}}$ and $R_{\mathrm{d}}$ to this state of abnormal physiological regulation. On the one hand, there is considerable evidence that $R_{\mathrm{d}}$ is markedly reduced in patients with NIDDM as compared with normal patients when measured during periods of physiological hyperinsulinemia $(1,2)$. On the other hand, after an overnight fast $R_{d}$ can be greater than normal in patients with NIDDM with significant fasting hyperglycemia (1). $R_{\mathrm{a}}$ has also been shown to be increased in such patients (3-9) and statistically significant correlations have been documented between measurement of $R_{\mathrm{a}}$ and fasting plasma glucose concentration ( $3,4,7-9)$. Based upon such considerations, it has been suggested that fasting hyperglycemia in NIDDM is due to an increase in $R_{\mathrm{a}}$, whereas the defect in $R_{d}$ accounts for postprandial hyperglycemia $(3,4,9,10)$. This generalization is primarily based upon studies performed in the morning, after an overnight fast, in which $R_{\mathrm{a}}$ is measured over an $\sim 2$-h period, i.e., from 8 to 10 a.m., and the observed value is correlated with plasma glucose concentration at 8 a.m. We were concerned about the results of studies carried out in this manner for two reasons. In the first place, the results of such experiments offer a relatively static view of nature, and do not provide any insight into the ongoing relationship that exists between $R_{\mathrm{a}}$ and $R_{\mathrm{d}}$. Secondly, we were concerned that $2 \mathrm{~h}$ was not long enough for tracer equilibrium to occur in patients with NIDDM and an expanded glucose pool size, thereby preventing accurate estimates of $R_{\mathrm{a}}(11)$. Indeed, we have indicated that it takes at least $4 \mathrm{~h}$ for tracer equilibrium to occur in patients with NIDDM (12). The present study was initiated to address both of these issues, and involved measurement of plasma glucose and insulin concentrations, $R_{\mathrm{a}}$ and $R_{\mathrm{d}}$ in normal subjects and patients with NIDDM continuously over a 16-h period, from 10 to 2 p.m. the next day. The results to be presented indicate that values for both $R_{\mathrm{a}}$ and $R_{\mathrm{d}}$ in patients with NIDDM differ from normal, but that the nature of these differences are quite time-dependent. Furthermore, the relationship between $R_{\mathrm{a}}$ and $R_{\mathrm{d}}$ varied continuously over the 16 -h period of observation in patients with NIDDM, as did their relative roles in the maintenance of the hyperglycemic state. As such, these data emphasize the complexity of the interplay between $R_{\mathrm{a}}$ and $R_{\mathrm{d}}$ involved in regulation of plasma glucose homeostasis. 


\section{Methods}

Eight patients with NIDDM and severe fasting hyperglycemia ( $>250$ $\mathrm{mg} / \mathrm{dl}$ ) and six normal individuals volunteered for this study. The two groups were similar in terms of age and degree of obesity (see Table I), and were in good general health with the exception of diabetes. They all gave informed consent and were admitted to the General Clinical Research Center at Stanford University Medical Center $24 \mathrm{~h}$ before the commencement of the study. All subjects were fed an isocaloric (35 $\mathrm{kcal} / \mathrm{kg}$ ) diet, containing (as percentage of total calories) $17 \%$ protein, $40 \%$ fat, and $43 \%$ carbohydrate, and each meal had this relative content of nutrients. Meals were eaten at 0800,1200 , and 1800 hours, and contained 20,40 , and $40 \%$, respectively, of the day's total caloric intake.

To quantify $R_{\mathrm{a}}$ and $R_{\mathrm{d}}$ each patient received an intravenous bolus of $30 \mu \mathrm{Ci} 3-\left[{ }^{3} \mathrm{H}\right]$ glucose at $8 \mathrm{p} . \mathrm{m}$. followed by a continuous infusion of radiolabeled glucose at a rate of $0.3 \mu \mathrm{Ci} / \mathrm{min}$ for the next $18 \mathrm{~h}$, or until 2 p.m. the following day. No food was allowed after 6 p.m. and blood was removed at 30 -min intervals from 8 until 2 p.m. the following day. Urine samples were also collected at 4-h intervals from 10 until 2 p.m.

Aliquots of plasma obtained at 30-min intervals were analyzed for plasma glucose (13) and insulin (14) concentration. In addition, aliquots were precipitated with $\mathrm{Ba}(\mathrm{OH})_{2}$ and $\mathrm{ZnSO}_{4}(15)$, and glucose and radioactivity were measured in the protein-free supernatant. Glucose specific activity was then determined, and the rate of glucose appearance $\left(R_{\mathrm{a}}\right)$ was calculated, using the non-steady state equations of Steele $(16,17)$. $R_{\mathrm{d}}$ was calculated from $\boldsymbol{R}_{\mathrm{a}}$, taking into account the change in plasma glucose concentration and the rate of urinary glucose loss. On two occasions the overnight studies were repeated, with the addition of an intravenous injection of $1 \mathrm{mg}$ of glucagon administered at midnight, $4 \mathrm{~h}$ after the start of the tracer infusion. Plasma radioactivity (in counts per minute per milliliters) was essentially identical on both nights, indicating that radiolabeled glucose was not being taken up and released to a degree significant enough to modify the experimental measurements.

Two-way analysis of variance (ANOVA) was used to evaluate differences in values of the two groups at various time points (18) using the Statistical Analysis System (SAS Institute, Inc., Cary, NC) on a VAX750 computer. When there was significant interaction between time and group, the difference at the individual time point was evaluated by the adjusted $t$ test of Bonferroni (19). Correlations between the experimental and the glucose levels were assessed by linear regressions, using Clinfo (Bolt, Beranek, and Newman, Inc., Cambridge, MA) on the VAX750. Data are expressed as mean \pm SEM.

\section{Results}

Mean ( \pm SEM) plasma glucose values at hourly intervals from 10 to 2 p.m. are shown in Fig. 1, and were significantly higher in patients with NIDDM throughout the 16-h period (two-way ANOVA, $P<0.001)$. Although plasma glucose concentration

Table I. Clinical Characteristics

\begin{tabular}{lcccc}
\hline & Age & BMI & FPG & FPI \\
\hline & $y r$ & $k g / m^{2}$ & $m g / d l$ & $\mu U / m l$ \\
Control (6) & $54 \pm 6$ & $26 \pm 1$ & $92 \pm 6$ & $25 \pm 8$ \\
NIDDM (8) & $54 \pm 4$ & $29 \pm 2$ & $329 \pm 21$ & $22 \pm 8$ \\
\hline
\end{tabular}

Data presented as mean \pm SEM. BMI, body mass index; FPG, fasting plasma glucose; FPI, FP insulin.

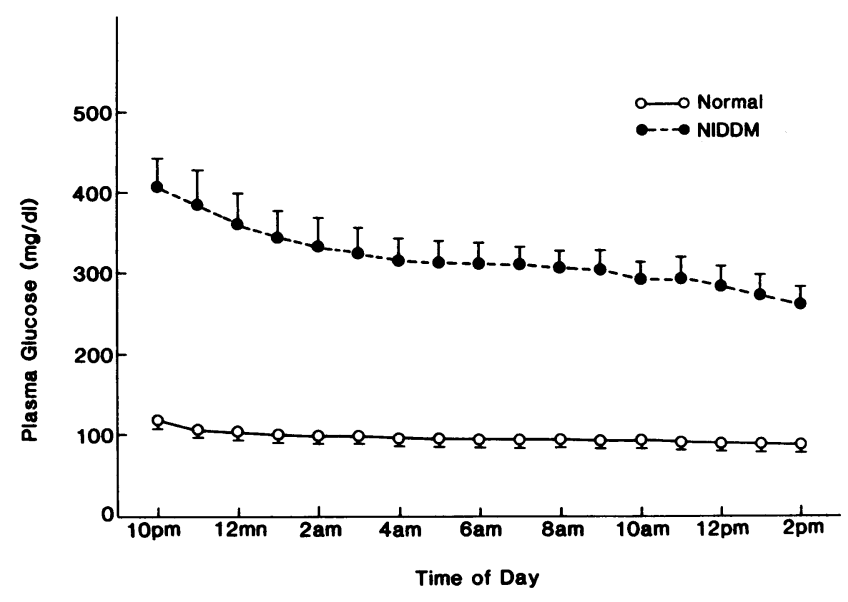

Figure 1. Mean ( \pm SEM) plasma glucose concentrations from 10 to 2 p.m. in normal subjects and patients with NIDDM.

fell progressively throughout the 16-h period of study in patients with NIDDM, significant hyperglycemia was still present in these individuals at the termination of the study. These data emphasize the progressive fall in plasma glucose concentration from 10 to 2 p.m. in patients with NIDDM, in contrast to the relatively stable glucose values in the individuals with normal oral glucose tolerance. In addition, this graph emphasizes the fact that plasma glucose concentration remained markedly elevated in patients with NIDDM throughout the study.

The change in plasma insulin concentration from 10 to 2 p.m. is illustrated in Fig. 2. Insulin concentrations were higher in the normal subjects when the study was initiated at 10 p.m., but fell rapidly from 10 p.m. to 2 a.m. Thus, plasma insulin concentrations were essentially identical in both groups for the majority of the $16-\mathrm{h}$ period.

The data in Fig. 3 show mean $( \pm \mathrm{SEM})$ values for $R_{\mathrm{a}}$ in the two groups from 10 to 2 p.m. These results indicate that $R_{\mathrm{a}}$ was higher than normal in patients with NIDDM at 10 p.m., and that the magnitude of the difference between the two groups is greatest at this time point. Values for $R_{\mathrm{a}}$ fell with time in both groups, but the rate and magnitude of decline in $R_{\mathrm{a}}$ was great-

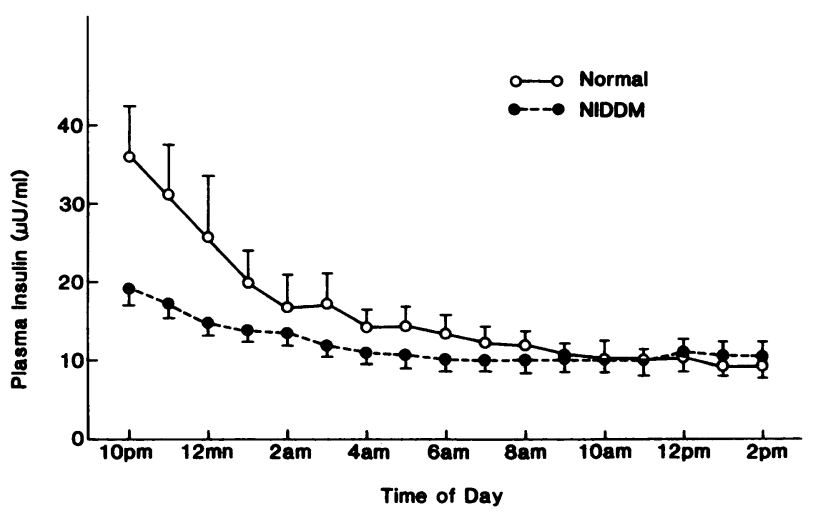

Figure 2. Mean ( \pm SEM) plasma insulin concentrations from 10 to 2 p.m. in normal subjects and patients with NIDDM. 


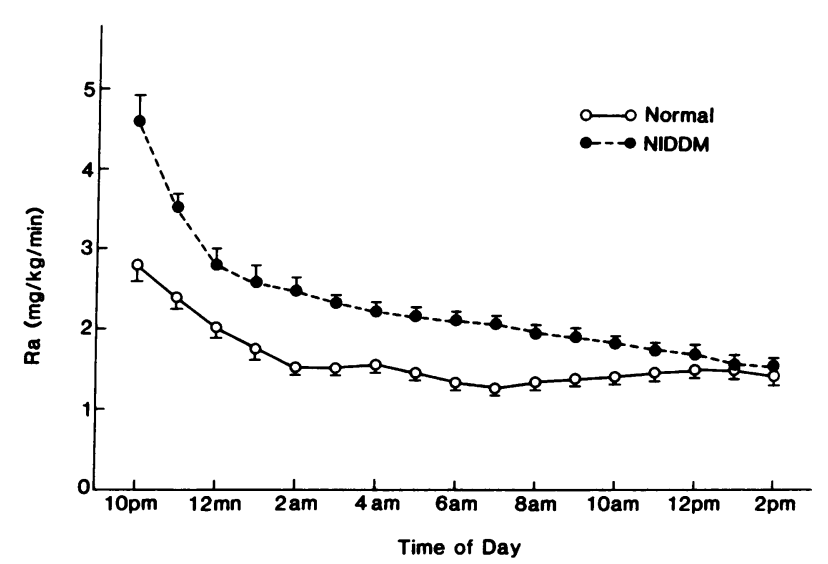

Figure 3. Mean ( \pm SEM) values of $R_{\mathrm{a}}$ from 10 to 2 p.m. in normal subjects and patients with NIDDM.

est in patients with NIDDM. As a result, the values for the two groups became more and more similar. $\boldsymbol{R}_{\mathrm{a}}$ values were significantly greater (two-way ANOVA, $P<0.001$ ) in patients with NIDDM from 10 to 2 p.m. In addition, there was a significant interaction between $R_{\mathrm{a}}$ and time $(P<0.001)$. Given the evidence of interaction, differences between $R_{\mathrm{a}}$ values of the two groups at each time point were evaluated by Bonferroni adjusted $t$ test (19). When this was done, $R_{\mathrm{a}}$ was significantly higher than normal in patients with NIDDM until 10 a.m. ( $P$ $<0.001-0.05)$. No differences were seen from 10 a.m. to 2 p.m.

$R_{\mathrm{d}}$ values in the two groups taken at hourly intervals throughout the experimental period are shown in Fig. 4, and when they were analyzed over the entire time period they were similar (two-way ANOVA). However, $\boldsymbol{R}_{\mathrm{d}}$ was higher in patients with NIDDM when the study began at 10 p.m., but lower in these same individuals when the measurements finished at 2 p.m. This evidence of interaction between $R_{\mathrm{d}}$ and time was confirmed statistically (two-way ANOVA, $P<0.05$ ). When $R_{\mathrm{d}}$ at individual time points was compared by the adjusted $t$ test of Bonferroni, $R_{\mathrm{d}}$ was higher in NIDDM at 10 p.m. $(P<0.01)$ and lower in NIDDM from noon to 2 p.m. $(P$

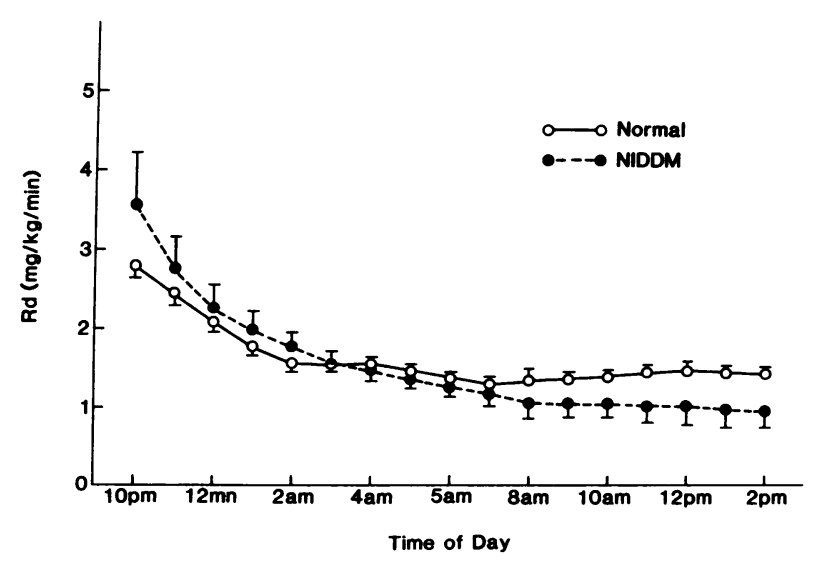

Figure 4. Mean ( \pm SEM) values of $R_{\mathrm{d}}$ from 10 to 2 p.m. in normal subjects and patients with NIDDM.
$<0.05)$. Values at all other time points were similar in the two groups.

\section{Discussion}

The results presented in this paper provide a different view of the relationship between $R_{\mathrm{a}}$ and magnitude of hyperglycemia in patients with NIDDM than that which seems to be generally held at this time. Several publications have documented a correlation between fasting plasma glucose concentration (measured at $\sim 8$ a.m.) and $R_{\mathrm{a}}$ (measured from 8 to 10 a.m.) (3, 4, 7-9), and concluded that hepatic overproduction of glucose is primarily responsible for maintenance of the enlarged plasma glucose pool in patients with $\operatorname{NIDDM}(9,10)$. The data in Fig. 1 shows that the plasma glucose pool size was approximately three times greater than normal at 2 p.m. Since values for $R_{\mathrm{a}}$ were similar at this same time in patients with NIDDM and normal individuals (Fig. 3), there was no longer any correlation between $R_{\mathrm{a}}$ and fasting plasma glucose at this juncture. Indeed, it is evident from comparison of the changes in plasma glucose and $R_{\mathrm{a}}$ that were seen from 10 to 2 p.m. that these two variables did not remain tightly correlated, but diverged increasingly as time elapsed. To put this into perspective, there was no statistically significant relationship between $R_{\mathrm{a}}$ and plasma glucose concentration in patients with NIDDM from 6 a.m. on. It must be emphasized that the relative ease with which we could disassociate $R_{\mathrm{a}}$ from plasma glucose concentration was because we observed their relationship over a 16-h period, not only at one point of time. Specifically, in previous studies $R_{\mathrm{a}}$ has usually been estimated by infusing [ ${ }^{3} \mathrm{H}$ ]glucose from 8 to 10 a.m., and using the non-steady state equations of Steele $(16,17)$ for calculation of $R_{\mathrm{a}}$. When this measurement was compared with the value seen in nondiabetics studied over the same time period, $R_{\mathrm{a}}$ was much higher in patients with NIDDM. However, these are precisely the conditions that are likely to lead to an overestimation of $R_{\mathrm{a}}$ in patients with NIDDM. The shorter the time period, and the greater the glucose pool size, the less likely it is that tracer equilibrium would be achieved. The longer the period of measurement after administration of tracer, the more likely that tracer equilibrium will be achieved, and a report from our laboratory has suggested that in order to obtain valid $R_{\mathrm{a}}$ values it is necessary to carry out the measurement for at least $4 \mathrm{~h}$ after the administration of tracer in patients with NIDDM (12). Given these considerations, it is not surprising that the magnitude of the difference between $R_{\mathrm{a}}$ in normal subjects and patients with NIDDM that we observed when measured from 8 to 10 p.m. in the present study was similar to that observed in previous studies carried out from 8 to 10 a.m. Thus, we believe that our inability to document significant correlations between $R_{\mathrm{a}}$ and plasma glucose concentration in the morning, in contrast to other investigators, is not a function of differences in our population of patients with NIDDM, but rather due to the overestimation of $R_{\mathrm{a}}$ as the result of tracer disequilibrium when measured after only $2 \mathrm{~h}$ in patients with an expanded plasma glucose pool size.

Another benefit of the experimental approach used in this study was to provide insight into the dynamic relationship between hepatic glucose production and plasma glucose and insulin concentration in NIDDM. It can be seen that $R_{\mathrm{a}}$ fell 
continuously from 10 to 2 p.m. in patients with NIDDM, eventually becoming equal to normal. This fall in $R_{\mathrm{a}}$ was paralleled by a reduction in plasma insulin concentration, and normal values for $R_{\mathrm{a}}$ were achieved when insulin levels were equal to normal. The decline in $R_{\mathrm{a}}$ that took place from 10 to 2 p.m. was also associated with a fall in plasma glucose concentration of over $100 \mathrm{mg} / \mathrm{dl}$. Thus, the lowest value for $R_{\mathrm{a}}$ coincided with the lowest plasma insulin and glucose concentrations. In other words, the combined suppressive effects of insulin and glucose were at their maximum when $R_{\mathrm{a}}$ was the highest in patients with NIDDM, and $R_{\mathrm{a}}$ fell to normal over a time frame in which the inhibitory effects of insulin and glucose were steadily declining. One possible explanation for these findings is that substrate load plays an important role in the regulation of $R_{\mathrm{a}}$. The data in Figs. 3 and 4 show that the fall in $R_{\mathrm{d}}$ parallels the decline in $R_{\mathrm{a}}$, and both are associated with a reduction in plasma glucose concentration. Hyperglycemia can compensate for resistance to insulin-stimulated glucose uptake by increasing $R_{\mathrm{d}}(20)$, and the fact that $\boldsymbol{R}_{\mathrm{d}}$ fell in conjunction with the decrease in plasma glucose is consistent with this formulation. Furthermore, $R_{\mathrm{d}}$, which was higher than normal in NIDDM at the start of our observations, was lower at the end. If a proportion of the excess glucose uptake seen in NIDDM from 10 p.m. to 10 a.m. was recycled back to the liver, in the form of lactate, for example, it could help explain the elevated $R_{\mathrm{a}}$ at that point. In this regard, it is noteworthy to remember that plasma FFA levels are also higher in patients with $\operatorname{NIDDM}(21,22)$, and that elevated FFA concentration has been associated with an increase in hepatic glucose production $(8,22,23)$. As plasma glucose concentration fell, $R_{\mathrm{d}}$ would be reduced, less lactate recycling would occur, and $R_{\mathrm{a}}$ would decline. This formulation raises the possibility that elevated values for $R_{\mathrm{a}}$ in patients with NIDDM may result from increased substrate flux to the liver. Whether or not this hypothesis is correct will depend upon additional measurements. However, at the moment it seems consistent with the experimental data presented.

Attention throughout this discussion has focussed on regulation of $R_{\mathrm{a}}$ in patients with NIDDM. However, in conclusion, some thought should be given to the implication these results have for regulation of plasma glucose pool size. It can be seen from Fig. 1 that patients with NIDDM were still severely hyperglycemic at the end of the period of measurement, despite having values for $R_{\mathrm{a}}$ that were similar to normal for the preceding several hours. These findings indicate that tissue glucose uptake was extremely abnormal. Indeed, tissue glucose uptake is not the only reason why the glucose pool size fell overnight, and urinary glucose excretion averaged $\sim 0.75 \mathrm{mg} / \mathrm{kg}$ per min over the last $12 \mathrm{~h}$. Since $R_{\mathrm{d}}$ only averaged $\sim 1.5 \mathrm{mg} / \mathrm{kg}$ per min over the same time period, $\sim 1 / 3$ of the fall in plasma glucose pool size was due to urine loss. As plasma glucose pool size approaches $180 \mathrm{mg} / \mathrm{dl}$, glucose loss via the kidney ceases, and the decline in plasma glucose pool size will be even slower. Indeed, it takes $\sim 72 \mathrm{~h}$ for plasma glucose pool size to reach normal levels in patients with NIDDM who are undergoing a total fast (24). Thus, the observed decrease in tissue glucose disposal must play an enormous role in the expanded glucose pool size of patients with NIDDM. Given this defect, relatively small increases in $R_{\mathrm{a}}$ will exceed the ability of an individual to maintain euglycemia. The fact that this increment in $R_{\mathrm{a}}$ may be essential for the transition from a marginal to a marked increase in glucose pool size should not obscure the magnitude of the defect in tissue glucose disposal in NIDDM, nor the essential role played by this abnormality in maintenance of the hyperglycemic state.

\section{Acknowledgments}

The authors wish to thank Ms. Mo-Oi Chang for her technical assistance, Ms. Yi Nina Chen for her statistical analysis using the computer, and Mrs. Valerie Lui and Mrs. Kathy Chewey for their secretarial assistance.

This work was supported by research grants from the National Institutes of Health (RR-70-22 and DK-30732) and the Nora Eccles Treadwell Foundation.

\section{References}

1. Reaven, G. M., Y.-D. I. Chen, C. C. Donner, E. Fraze, and C. B. Hollenbeck. 1985. How insulin resistant are patients with noninsulin dependent diabetes mellitus. J. Clin. Endocrinol. \& Metab. 61:32-36.

2. Reaven, G. M. 1983. Insulin resistance in noninsulin-dependent diabetes mellitus. Does it exist and can it be measured? Am. J. Med. 74:3-17.

3. Bowen, H. F., and J. A. Moorhouse. 1973. Glucose turnover and disposal in maturity-onset diabetes. J. Clin. Invest. 52:3033-3045.

4. Forbath, N., and G. Hetenyi, Jr. 1966. Glucose dynamics in normal subjects and diabetic patients before and after a glucose load. Diabetes. 15:778-789.

5. Jacobs, G., G. Reichard, E. H. Goodman, Jr., B. Friedmann, and S. Weinhouse. 1958. Action of insulin and tolbutamide on blood glucose entry and removal. Diabetes. 7:358-369.

6. DeFronzo, R. A., D. Simonson, and E. Ferrannini. 1982. Hepatic and peripheral insulin resistance: a common feature of type 2 (non-insulin-dependent) and type 1 (insulin-dependent) diabetes mellitus. Diabetologia. 23:313-319.

7. Best, J., R. Judzewitsch, M. Pfeifer, J. Beard, J. Kolter, and D. Porte, Jr. 1982. The effect of chronic sulfonylurea therapy on hepatic glucose production in non-insulin dependent diabetes. Diabetes. 31:333-338.

8. Bogardus, C., S. Lillioja, B. V. Howard, G. Reaven, and D. Mott. 1984. Relationships between insulin secretion, insulin action and fasting plasma glucose concentration in non-diabetic and non-insulin dependent diabetic subjects. J. Clin. Invest. 74:1238-1246.

9. Revers, R., R. Fink, J. Griffin, J. Olefsky, and O. Kolterman. 1984. Influence of hyperglycemia on insulin's in vivo effects in type II diabetes. J. Clin. Invest. 73:664-672.

10. Firth, R. G., P. M. Bell, H. M. Marsh, I. Hansen, and R. A. Rizza. 1986. Postprandial hyperglycemia in patients with non-insulin-dependent diabetes mellitus. Role of hepatic and extrahepatic tissues. J. Clin. Invest. 77:1525-1532.

11. Chen, Y.-D. I., A. Golay, A. Swislocki, and G. Reaven. 1986 How do you measure endogenous glucose production in non-insulin dependent diabetes mellitus (NIDDM)? Clin. Res. 34:102a. (Abstr.)

12. Chen, Y.-D. I., A. L. M. Swislocki, C.-Y. Jeng, J.-H. Juang, and G. M. Reaven. 1988. Effect of time on measurement of hepatic glucose production. J. Clin. Metab. In press.

13. Kadish, A. H., R. L. Litle, and J. C. Sternberg. 1968. A new and rapid method for determination of glucose by measurement of rate of oxygen consumption. Clin. Chem. 14:116-131.

14. Desbuquois, B., and G. D. Aurbach. 1971. Use of polyethylene glycol to separate free and antibody bound peptide hormones in radioimmunoassays. J. Clin. Endocrinol. \& Metab. 33:732-738.

15. Somogi, M. 1945. Determination of blood sugar. J. Biol. Chem. 160:69-73.

16. Steele, R., J. Wall, R. deBodo, and N. Altszuler. 1956. Measure- 
ment of size and turnover rate of body glucose pool by the isotope dilution method. Am. J. Physiol. 187:15-24.

17. deBodo, R., R. Steele, N. Altszuler, A. Dunn, and J. Bishop. 1963. On the hormonal regulation of carbohydrate metabolism: studies with ${ }^{14} \mathrm{C}$-glucose. Recent Prog. Horm. Res. 19:445-488.

18. Winer, B. J. 1971. Multifactor experiments having repeated measures on the same elements. In Statistical Principles in Experimental Design. 2nd ed. McGraw-Hill Book Company, New York. 514-603.

19. Godfrey, K. 1985. Statistics in practice. Comparing the means of several groups. N. Engl. J. Med. 313:1450-1456.

20. Doberne, L., M. S. Greenfield, M. Rosenthal, A. Widstrom, and G. M. Reaven. 1982. Effect of variations in basal plasma glucose concentration on glucose utilization $(\mathrm{M})$ and metabolic clearance (MCR) rates during insulin clamp studies in patients with non-insulin-dependent diabetes mellitus. Diabetes. 31:396-400.
21. Fraze, E., C. C. Donner, A. L. M. Swislocki, Y.-A. M. Chiou, Y.-D. I. Chen, and G. M. Reaven. 1985. Ambient plasma free fatty acid concentrations in non-insulin-dependent diabetes mellitus: evidence for insulin resistance. J. Clin. Endocrinol. \& Metab. 61:807-811.

22. Golay, A., A. L. M. Swislocki, Y.-D. I. Chen, and G. M. Reaven. 1987. Relationships between plasma free fatty acid concentration, endogenous glucose production, and fasting hyperglycemia in normal and non-insulin dependent diabetic individuals. Metab. Clin. Exp. 36:692-696.

23. Ferrannini, E., E. J. Barrett, S. Bevilacqua, and R. A. DeFronzo. 1983. Effect of fatty acids on glucose production and utilization in man. J. Clin. Invest. 72:1737-1747.

24. Greenfield, M., O. Kolterman, J. M. Olefsky, and G. M. Reaven. 1978. The effect of ten days of fasting on various aspects of carbohydrate metabolism in obese diabetic subjects with significant fasting hyperglycemia. Metab. Clin. Exp. 27(Suppl. 2):1839-1851. 